\title{
Sartículos
}

\section{La iglesia Parroquial de San Sebastián de Cañete la Real en la Edad Moderna, a través de las visitas pastorales e inventarios parroquiales}

\author{
Eduardo Asenjo Rubio \\ Universidad de Málaga
}

RESUMEN

Este artículo está en la línea del anterior ${ }^{1}$, aportando nuevos datos sobre la arquitectura religiosa del norte de la provincia de Málaga, adscrita a la antigua Archidiócesis de Sevilla. El análisis se centra en la actual localidad de Cañete la Real.

PALABRAS CLAVE: Patrimonio Cultural/ Arquitectura Religiosa.

Saint Sebastiane's Parish Church in Cañete la Real into Modern Age through Books of Pastoral Visitations and Inventories.

ABSTRACT

This article is in the line of the previous one, contributing new information on the religious architecture of the north of the province of Malaga, assigned to the former Archidiocese of Seville. The analysis centres on the current one locality Cañete la Real.

KEY WORDS: Cultural Heritage/ Religious Architecture.

Adiciones a la historia constructiva de la ParRoguia de SAN Sebastián de Cañete la Real.

Para conocer la historia de la parroquia de San Sebastián es imprescindible hacer referencia a dos obras de Rosario Camacho, pionera en documentar el largo y a veces embrollado proceso constructivo de esa fábrica ${ }^{2}$, como podrá comprobarse a lo largo de este artículo, sobre todo por lo habitual a la hora de incumplir los mandatos de visitas y su acumulación en el tiempo, prologándose durante años algunas de las mejoras planteadas. Para comprender con mayor claridad la exposición de este artículo, he querido seguir un orden cronológico, atendiendo principalmente

* ASENJO RUBIO, Eduardo: "La iglesia Parroquial de San Sebastián de Cañete la Real en la Edad Moderna, a través de las visitas pastorales e inventarios parroquiales", en Boletín de Arte, $\mathrm{n}^{\circ} 29$, Departamento de Historia del Arte, Universidad de Málaga, 2008, págs. 197-214.

1 ASENJO RUBIO, E.: "Aportaciones al estudio del Patrimonio Cultural de Málaga." Boletín de Arte n 22 , Departamento de Historia del Arte, Universidad de Málaga, págs. 135-158.

2 CAMACHO MARTÍNEZ, R.: Málaga Barroca. Arquitectura religiosa de los siglos XVII y XVIII. Universidad de Málaga, Colegio de Arquitectos de Andalucía Oriental, Excma. Diputación Provincial. Málaga 1981. Arquitectura Religiosa en Cañete la Real. Málaga. Centro de Ediciones de la Diputación de Málaga (CEDMA), 1997. 
a los datos que ofrecen las visitas, independientemente de que éstas se refieran a la construcción de la parroquia o a la dotación de bienes muebles. Sólo de este modo podrá tenerse una imagen en paralelo de lo que ocurría en la edificación del templo, sus avances y retrocesos, como en su amueblamiento ${ }^{3}$.

Como afirma la doctora Rosario Camacho es difícil conocer la fecha exacta de la construcción de la parroquia de San Sebastián 4 . De hecho, un inventario de los bienes de dicha parroquia realizado el uno de enero de 1927 es bastante claro al respecto, simplificando que ese templo había sido construido durante los siglos XVIII y XIX5.

Sin embargo, existen abundantes e interesantes noticias sobre esta parroquia que se han conservado en el Archivo Histórico Provincial de Málaga, sobre todo en los legajos que comprenden los protocolos notariales de Cañete la Real, como en las diferentes secciones que integran el Archivo General del Arzobispado de Sevilla6, con especial referencia a los Libros de Visitas; y todo ello permite reconstruir parte de la historia de este inmueble y conocer a través de sus documentos, los acontecimientos que condicionaron sus diferentes fases de construcción. Todo el siglo XVIII y el XIX está bien documentado, sin embargo en las centurias del XVI y XVII la información es bastante escasa. Las visitas pastorales que se realizaron a lo largo del tiempo tienen una importancia muy significativa, no sólo como información puntual, sino como base para análisis de períodos más largos, en donde pueden advertirse los diferentes cambios arquitectónicos y ornamentales que se produjeron en esta parroquia, la dotación de nuevos bienes muebles, entre otros aspectos.

D. Cayetano Espinosa, párroco de San Sebastián, en el inventario referido de 1927 informa que en 1613 se consignan en los libros de "Visitas" conservados en el archivo de la iglesia, las primeras cuentas de la construcción del centro de la iglesia y en 1747 se había terminado la parte inferior hasta la fachada, fechas que hasta el momento se desconocían con exactitud? ${ }^{7}$.

A finales del siglo XVII, se observa a través de las relaciones de las visitas ad limina un buen ritmo e intensidad en la programación del amueblamiento de la iglesia de San Sebastián. En la visita realizada el 21 de diciembre de 1685 se dejaron provistos varios mandamientos, como el encargo de dos confesionarios, componer

\footnotetext{
3 Debido a la importancia y amplitud documental existente sobre las diferentes fases constructivas de la iglesia de San Sebastián, estoy realizando una publicación cuyo análisis es más amplio que el que se presenta en este artículo.

4 CAMACHO MARTÍNEZ, R.: Málaga Barroca..., pág. 512.

5 Archivo General de la Archidiócesis de Sevilla (A.G.A.S). Sección IV Administración General. Serie Inventarios, legajo 14.573, pieza n. 57.

6 En el año 2001 se publicó la primera parte de este artículo, cuya investigación principal se centraba en los fondos del Archivo General del Arzobispado de Sevilla. Después de varios años de intensa reforma de una parte del edificio como de los fondos, los documentos han rebido signaturas nuevas. Agradezco nuevamente a Isabel González Ferrin y a Nuria Torres, archiveras, así como a Manuel Zambrana Ruiz, auxiliar de archivo, por su labor profesional.

7 Es singularmente relevante esta información, porque en ese año no se había producido la destrucción de iglesias y conventos, previo a la Guerra Civil, y la consiguiente quema de sus archivos. De este modo, el párroco pudo ver y comprobar de primera mano dicha información.
} 
la pila bautismal; aunque quizás el más interesante fuera la disposición sobre el Sagrario que debía hacerse para el nuevo altar mayor. También se debía hacer otro Sagrario comulgatorio para el altar de Nuestra Señora de la Concepción ${ }^{8}$.

En la visita celebrada el 1 de mayo de 1692 se reiteraron algunos de los mandamientos anteriores, como por ejemplo la orden número 19: "Que en la mayor boveda se acabe el Sagrario que se esta haciendo de nuevo para el altar mayor y se coloque y ponga con la decencia que le previene en el segundo mandado de la visita pasada9".

En otra visita de finales del siglo XVII hay que destacar diversas noticias sobre la ubicación del inmueble y la descripción correspondiente de la fábrica, enumerándose interesantes datos, como la identificación de los bienhechores y caudales más importantes de la villa. En el primer punto se describe que Cañete la Real está en un llano que hace la sierra, a una legua de distancia de Teba. Se trataba de un lugar rico con una vega de "admirables tierras, ganados y ay personas de muchas obligaciones y caudales". Respecto a la iglesia describe que "no tiene más de medio cuerpo pero es de admirable y robusta fábrica, aviase hecho altar mayor que ya se estaba dorando. La sacristía es mala pero esta en animo de hacerla nueva en concluiendo la obra principal, los retablos son buenos y las imagenes devotas... 10". Había cuatro ermitas, la de los Remedios, del Carmen, de Jesús y de San Marcos. De todas ellas sólo las dos primeras coinciden con las que se mencionan en la visita de 1786. En los conventos de San Francisco y en el de Carmelitas había 25 monjes y 20 monjas. El informe señalaba a D. José Linero como uno de los eclesiásticos más ricos de la villa.

En la visita del 11 de mayo de 1705 hay que destacar dos mandatos interesantes, uno referido al altar mayor de Nuestra Señora de la Concepción, y la conversión en aceite de los arrendamientos de las tierras que estaban vinculadas a dicha imagen, ya que parecía que no se estaba aplicando a esa finalidad, por lo que se había determinado que el eclesiástico correspondiente lo administrase para la liquidez de la fábrica, como se desprende del siguiente comentario:

“...pues cabe en los desempeños y caudal que hoy tiene se forme en la torre un chapitel, no solo a cuanto conduce a la hermosura de dicha torre, sino es tambien porque en la intemperie de este pays hay sobrada experiencia de los riesgos de las campanas y de la continuación de las aguas con la injuria de los temporales viven la torre ${ }^{11}$ ".

En la visita realizada en 1706 se plasmaron 23 disposiciones, todas ellas de gran interés, entre otras razones, porque informan sobre los bienes muebles, una

\footnotetext{
8 A.G.A.S, Sección II Gobierno, Serie Libros de visitas, legajo 05161, año 1686-1689.

9 A.G.A.S, Sección II Gobierno, Serie Libros de visitas, legajo 05162, año 1691-1693.

10 A.G.A.S, Sección II Gobierno, Serie Libros de visitas, legajo 05165, año 1694-1700.

11 A.G.A.S, Sección II Gobierno, Serie Libros de visitas, legajo 05174, año 1706-1816.
} 
documentación que permite comprender las diferentes opciones estéticas que presentaba el interior del edificio, su distribución, prioridades, el ornamento para la liturgia o el adoctrinamiento de la población que se hacía a través de ellos, la elección y advocación de las capillas, entre otros aspectos. Además, este documento tiene un valor bien indicativo, en la medida que señala en el margen si dicha orden se realizó o si quedaba pendiente para la siguiente visita, pero también, y como es el caso, muchos de los mandamientos no se hicieron a causa de la construcción del inmueble, con lo cual la estrecha relación entre obra y amueblamiento queda perfectamente relacionada y supeditada a los ritmos constructivos. De esas 24 disposiciones, sólo 4 no se hicieron por motivo de las obras en la iglesia, 14 se cumplieron y 6 se incumplieron.

Del primer grupo destaca: el mandato primero que se refiere a las puertas del sagrario del altar mayor, al que debía ponerse unos goznes más pequeños para su mejor ajuste y evitar que entraran las sabandijas, así como dorar el ribete que estaba pegado a la planicie en la parte interior, porque causaba un efecto de fealdad el hecho de no estar dorado, y que con cuatro panes de oro podía remediarse. El cuarto mandato expresaba que se comprara una cajita para pectoral y llevar a Cristo sacramentado "de secreto", que fuese dorado y se dispusiera en la tapa un jeroglífico del Santísimo. Para realizarlo se debía dar en pago la que tenía la iglesia, porque era muy pequeña y porque costaba sacar la sagrada forma. Una vez hecho el pectoral se pondría en una bolsa de tela rica con sus cordones para que el sacerdote lo portara con la máxima decencia. En cuanto al cáliz torcido y una taza de plata que estaba en poder del mayordomo, al ser inservibles, debía hacerse uno nuevo, disponiéndose que la copa se dorase por dentro. Sin embargo, antes de realizarlo había que pesar dicho cáliz y taza, para que el que entregara el platero fuera del mismo peso. El sexto mandato consistía en aplicar las maderas sobrantes del armario para el archivo y realizar un cancel para la puerta colateral de mano derecha, debido a que en esa zona los aires batían con fuerza y apagaba las lámparas y velas de los altares. Es significativo que se pidiera que el cancel no fuera de escultura, ni de otro modo costoso, sino sólo decente que reparara el daño sufrido, pensando más en una intervención provisional que definitiva. El mandamiento 23 pide al mayordomo que comprara sillas de basqueta de moscovia con clavazón dorada y de fábrica primorosa para ponerlas en el presbiterio, y que se quitaran las de madera por estar feas e indecentes.

De los mandamientos que se cumplieron, la construcción de un armario en forma de escaparate que sustituyera las taquillas que conservaban la prolija documentación de la parroquia, es quizás uno de las más interesantes. Se hizo el armario debido al estado de humedad que presentaban los documentos y para evitar su progresivo deterioro.

Le sigue un amplio grupo de mandamientos referidos a la ropa de la iglesia: casullas, ternos y toallas, que en su mayoría se encontraban en mal estado y se sustituyeron por otras o bien se pasaron los bordados a otras piezas nuevas.

Revisando la documentación existente sobre la historia constructiva de la parroquia de San Sebastián da la sensación de haber existido una "mano negra" en 
lo referente a la pérdida de informes sobre algunas visitas y cumplimientos de mandatos dispuestos por los maestros de fábricas. Un documento de 1715 recoge el estado ruinoso de la "vieja" iglesia, habiéndose dispuesto la construcción de una nueva, cuyo nuevo eje se disponía en dirección opuesta a la primitiva ${ }^{12}$. El maestro de obras en aquellos años era Diego Antonio Díaz, uno de los arquitectos más significativos de la primera mitad del setecientos del barroco andaluz, y especialmente de Sevilla. Recientemente, la recuperación de varios documentos ha permitido conocer el estado constructivo de la parroquia de San Sebastián. El 7 de mayo de 1716 Martín Pérez Mayor en nombre de la fábrica de la iglesia de Cañete la Real en los autos con el deán y cabildo de la iglesia metropolitana de Sevilla sobre el embargo de las cuartas partes del diezmo para la obra que se debía realizar en dicha parroquia, pidió al licenciado D. Francisco de Arroyo, procurador mayor del deán y cabildo de la Catedral de Sevilla, que entregara los autos que se había llevado. Respondió que no estaban en su poder a pesar de haberlos buscado. Entonces se determinó que el procurador mayor costease una nueva visita a dicha iglesia, declarando el estado y la calidad del inmueble. El auto solicitaba al maestro mayor de fábricas que declarase el estado de la iglesia, las obras y reparos que necesitaba "con la misma expresión que hizo la primera y la haga ante el presente notario"13. Es muy significativo que en el mismo documento expresara que el maestro mayor de "fábricas "remendo borradores... y pudiendo hacer otra visita declare el estado de la iglesia14." De hecho, en la declaración de 9 de mayo de 1716 del maestro Diego Antonio Díaz "se acuerda" de la ruina que amenazaba a la iglesia y el reparo de la nueva ${ }^{15}$. Debido al estado ruinoso de la iglesia vieja, ésta no admitía ningún tipo de reparos, a no ser que se hiciera de nuevo el tejado, lo cual significaría un gasto considerable, además de un gasto absurdo "por rason de que esta atravesada en la delantera de la nueba por cuia causa tienen mala salida las aguas, y pudriran las dichas paredes y enmaderados que se hisieren, y dentro de pocos años bolbera a suceder la mesma ruina, y porque dicha Iglesia viega es interina asta que se acabe de seguir la Nueba que le falta un entercolumnio, y puerta principal que es lo que se debe aser $16 . "$

Continuando con el análisis del documento, en un informe fechado el 6 de agosto de 1715, la Diputación de Negocios informó al cabildo que Diego Antonio Díaz se había excedido en su cometido, presupuestando un gasto de 3.000 ducados para el arreglo del tejado ${ }^{17}$. Sin embargo, un año después el maestro mayor de fábricas pudo cambiar esta información, mejorándola y teniendo en cuenta que la decla-

\footnotetext{
12 CAMACHO MARTíNEZ, R.: Málaga Barroca..., pág. 512.

13 A.G.A.S. Sección III: Justicia. Serie: Fábrica, Pueblos, legajo 11.766.

14 Ibidem, s/f.

15 Con lo cual no se realizó una segunda visita, sino que el maestro mayor de fábricas hizo un ejercicio memorístico para recomponer la primera visita.

16 A.G.A.S. Sección III: Justicia. Serie: Fábrica, Pueblos, legajo 11.766.

17 CAMACHO MARTÍNEZ, R.: Málaga Barroca...,pág. 512.
} 
ración se hizo de memoria: "porque en todo tiempo aunque se aga el reparo de la vieja siempre en adelante es presiso que se siga y se acabe la Iglesia Nueba por cuia rason mas bale, y es importante el que lo que se abia de gastar en este infrutuoso reparo se gaste en proseguir la dicha Iglesia Nueba en que se gastara de nueve a diez mil ducados, y es contra conciencia gastar en reparos de lo que en adelante no a de serbir, mas de tres mil ducados por lo qual, y estar amenazando prosima ruina de que suceda una des[gra]sia conbiene y soy de parecer que aunque al presente no se puede proseguir la obra de la dicha Yglesia nue[ba] se demuela y deribe la viega, y que en ella no se gaste nada sino es lo que fuere necesario para los cerramientos de la nueba interin que no se acabe de labrar... ${ }^{18}$. Finalmente por auto de 9 de mayo de 1716 se mandó que se prosiguieran las obras de la iglesia nueva, como estaba mandado en los autos que se habían perdido, embargándose las cuartas partes de los diezmos. Se mandaba que derribara la iglesia vieja y se hicieran los tabiques necesarios para celebrar los divinos oficios. Las obras de demolición no se iniciaron hasta el 3 de junio de ese año ${ }^{19}$.

También las visitas se hicieron eco de la problemática de la construcción de la parroquia de San Sebastián en 1715, año que debió de ser determinante para la buena marcha de las obras. El informe del visitador de 18 de abril de 1715 aporta más información al respecto, ya que pudo comprobar como la iglesia antigua aún descansaba sobre la nueva, lo que estaba provocando el hundimiento de los techos de la primera. Esta situación in extremis hizo que se llamase a un maestro alarife de Cañete para que reconociera los daños y a un maestro carpintero de Sevilla, que en ese momento se encontraba trabajando en Teba. La declaración de ambos coincidía en que se debía derribar toda la techumbre de las tres naves y volverla a hacer, y sin que de la iglesia vieja pudiera aprovecharse ni una sola teja. Presupuestaron las obras en 28.000 reales; sin embargo, las arcas de la fábrica se encontraban agotadas debido a que en los últimos años los caudales se habían empleado en el "aderezo y ultimo cuerpo que se hizo de la torre en virtud de los autos que se siguieron ante el provisor..." costeando el provisor de su propio caudal 33.000 reales de vellón 20 . Se proveyó por vía de mandato que el mayordomo de fábrica, que entonces era Juan de Milla, pidiera ante el provisor que se remediara el problema del techo, aplicándose o bien las cuartas decimales o el modo que se estimara más conveniente, dejándose como prueba la declaración de los maestros. Siendo visitador general del Arzobispado de Sevilla D. Gregorio Luis Zapata y Palafox se pasó auto el 27 de abril de 1715 con la declaración de los maestros Pedro Sánchez [Arvar], maestro carpintero vecino de la ciudad de Sevilla, en compañía de Alonso Domínguez, maestro alarife. La situación era la siguiente: la madera se encontraba podrida y vencido el techo por haberse arruinado y descargado sobre el arco toral de

18 A.G.A.S. Sección III: Justicia. Serie: Fábrica, Pueblos, legajo 11.766.

19 CAMACHO MARTÍNEZ, R.: Málaga Barroca..., pág. 512.

20 A.G.A.S, Sección II Gobierno, Serie Libros de visitas, legajo 05184, año 1713-1714. 
la capilla mayor de la iglesia vieja, lo que había originado que la iglesia nueva recibiera un gran daño a causa de la armadura y colgadizo de la nave que venía sobre la iglesia nueva "y van correspondiendo dos pilares principales y las paredes maestras de afuera una y otro por coger y atravesar su longitud una canal maestra que atraviesa todo su ancho y fachada de la iglesia nueva." La seguridad de la techumbre no se solucionaba con apuntalarla, según el juicio de los maestros consultados, ya que con la fuga de los puntales se movería la obra. Tras el reconocimiento de Alonso Domínguez sobre las paredes de la iglesia vieja, arcos y pilares, dictaminó que se hallaban "firmes y suficientes" como el edificio nuevo, y no le causaba daño alguno a la iglesia nueva, "ni otro defecto más que el de asombrarle que la tiene por delante prolongada y que todo el daño y peligro viene amenazada únicamente por el techo." Valoró el material de la iglesia vieja en 2.500 ducados 21.

En la visita de 1721 se relata como hacía seis años que se había librado la cuarta parte de los diezmos de la villa de Cañete la Real para la perfección y último remate de la iglesia, a la que sólo le faltaba poco más de un arco. En ese año su estado era el siguiente: se habían levantado algo las paredes, y "en todo se va con mucha lentitud" y debido a la tardanza, los interesados habían iniciado un pleito contra el administrador D. Martín de Arana. La torre se encontraba reparada22.

En un voluminoso corpus documental que integra diferentes fases constructivas de la parroquia de Cañete la Real, el arquitecto Silvestre Tirado refiriéndose a la portada de la iglesia dice que es de piedra del Señorío de Jomillos, la mejor que había por esos parajes, a una distancia de dos leguas de la villa. Las obras de la portada se habían empezado el 19 de mayo de 1728. Diego Antonio Díaz, arquitecto, fue a visitar y a reconocer la obra que se había hecho, lo que faltaba por realizar y lo necesario para su conclusión, dejando un informe muy completo y sumario. Hasta ese momento sólo se había labrado una columna jónica, faltando el arquitrabe, friso, cornisa, frontis, remate y el cuerpo del nicho para San Sebastián. También debía concluirse el enlucido de la pared de yeso blanco y debajo sobre el "fahardo" de cal y arena se debía "desharrar" de yeso prieto arreglada y a plana para que saliera perfecto el enlucido. Aún estaban por realizar las siguientes obras: portada, enlucido de las fachadas, puerta principal, cañón de la bóveda central y nave lateral, toda la solería de ladrillo tosco revocado y la capilla bautismal. La sacristía en el testero del crucero de la nave de la epístola que llamaban del Rosario por detrás del altar mayor, y en la capilla del Rosario se debía hacer otro cuarto taller para guardar las alhajas. Otro elemento aún sin realizar era la lonja que circundaría el templo por su fachada principal, así como por las dos colaterales. Tasó la obra en 10.000 reales.

En la visita de 1730 puede observarse un avance progresivo de las obras a diferentes niveles, como también el control minucioso del gasto, para lo que el provisor dictaminó severas medidas. El mandato sexto se refería a los enterramientos

21 Ibídem. s/f.

22 A.G.A.S, Sección II Gobierno, Serie Libros de visitas, legajo 05190, año 1721. 
en la iglesia parroquial, motivado por la solicitud de varios lugares y sitios en la nave de en medio y otra en la capilla mayor. El modo de sepultura era con o sin caja. EI problema de los enterramientos, además del gasto que suponía de cal y ladrillo, era el deterioro de la nueva solería. El cómputo de las sepulturas era el siguiente: Se aumentó 23 sin caja, y 30 con ella. En la nave de en medio había 46 sin caja y 60 con ella. En la capilla mayor había de las dos. En otros mandatos se señaló la necesidad de vestuario. En relación al estado de la fábrica, en ese año todavía tenía embargada la cuarta parte para la obra que se estaba haciendo en la iglesia, y según valoración del provisor "la que acabada será muy hermosa". Se estaba fabricando la torre y las campanas, ya que las que antes tenían estaban quebradas, y una devota había dejado por vía testamentaria 300 ducados para su ejecución, con el cargo de dos misas. Otro mandato señalado consistía en que el vicario prohibiera, a no ser que fuera urgente, que el mayordomo de la fábrica gastara el dinero en encerados para las ventanas de la parroquial a las que se les había puesto vidrios a costa de la cuarta parte, y se precisaba todo el caudal para concluir las obras, ya que con motivo de la construcción de la torre se encontraba al descubierto casi un testero de la iglesia. Por lo tanto, no había necesidad de hacer un gasto tan elevado y por consiguiente que no se abonara en la cuenta23.

El 24 de octubre de 1741 el arquitecto Silvestre Tirado visitó la iglesia para reconocer, entre otras obras, la sacristía y su entrada, el cuarto de las alhajas, lugares comunes, las tres naves, el coro, cuya obra había sido rematada en Juan Eusebio Sánchez, maestro de carpintería 24 .

Una de las primeras noticias sobre el estado de conservación de la nueva iglesia es un documento fechado en 1757, firmado por el estado religioso, el consejo, la justicia y el regimiento de la villa de Cañete, con motivo de los estragos ocasionados durante el terremoto de 1755. La información va más allá del mero relato de las pérdidas, y aporta otro tipo de datos, como la procesión que se realizó para el traslado del sacramento, lo que permite conocer el itinerario procesional, y sus consecuencias en la sacralización del espacio público y, por ende, una característica bastante común en la sociedad del Antiguo Régimen.

Los asistentes declararon como una única voz bajo la protección soberana de la Virgen María, que el uno de noviembre de 1755 sobre las nueve o diez de la mañana se produjo un fuerte terremoto con un radio de acción amplio ${ }^{25}$. En una valoración genérica sobre lo sucedido se relata que muchas ciudades y pueblos del reino se habían arruinado, "levantados sus edificios", perdidas muchas personas y caudales. La habitual sugestión en la que vivía la sociedad de la época, cuando una catástrofe arremetía contra personas y bienes, se ilustra de un modo excepcional en el siguiente párrafo: “...todo dimanado de nuestras culpas con que tenemos ofendido a

23 A.G.A.S, Sección II Gobierno, Serie Libros de visitas, legajo 1376, año 1730-1732.

24 A.G.A.S. Sección III: Justicia. Serie: Fábrica, Pueblos, legajo 11.767.

25 ARANGO GONZÁLEZ, J. R.: Análisis de terremotos históricos por sus efectos. El terremoto de Andalucía. Centro Internacional de Métodos Numéricos en Ingeniería. Barcelona 1995. 
Nuestro Amantísimo Dios, quien mirando a esta villa y sus vecinos con su misericordia, solo fue un amago de su divina justicia, pues merecíamos, por nuestros defectos ser sumergidos en los abismos; y solo padecio en tan gran conflicto las casas de Nuestro dios..."26.

Significativa es la breve, pero concisa descripción de la situación en la que quedó la iglesia de San Sebastián, "cuarteándole sus bóvedas y postes, dejándola tan maltratada...", por lo que se trasladó el Santísimo Sacramento a la ermita de Nuestra Señora de El Carmen. También se llevaron en procesión las imágenes de Nuestra Señora del Rosario y de la Aurora. Otro de los inmuebles religiosos afectados por el terremoto fue el convento de Nuestro Padre San Francisco, destejándole la mayor parte de los tejados y otras oficinas.

Para remediar la ira divina, pero también sus beneficios, la villa de Cañete la Real acordó hacer un voto en la fiesta de todos los santos y cortesanos del cielo. De este modo, reunidos ambos cabildos en la Iglesia parroquial se decidió salir procesionalmente cantando como rogativa las letanías de los santos. Se hizo estación en la ermita de Nuestra Señora de El Carmen:

“... sitio donde nos refugiamos todo el tiempo que Nuestra Iglesia Parroquial estuvo sin uso, a causa del terremoto expresado, $Y$ desde dicha ermita se vuelva Prosecionalmente del mismo modo a Nuestra Iglesia Parroquial, Y se haga fiesta estando patente el santísimo sacramento Nuestro Dueño y Señor, y su madre santísima con misa cantada y sermón, costeándose por ambos cabildos por mitad. $Y$ asi se practtico en el año proximo pasado de setecientos cincuenta y seis, y asi se ha de hacer en este presente año de la fecha, continuandose en lo subsesivo el referido dia para siempre jamas, vajo del voto que hacemos en esta escriptura a su majestad..."27.

Como consecuencia del terremoto y lo maltrecha que había quedado la fábrica parroquial en 1755 Tomás José Zambrano tuvo que "derribar tres bóvedas de cada nave de los lados próximos a la capilla mayor, por estar muy quebrantadas y fuera de su punto" 28 . El presupuesto de éstas y otras obras, como la de la sacristía ascendieron a 14.450 reales.

Detrás de ese expediente -en el folio 16- hay una declaración de Ignacio de Bogas, maestro de albañilería de la ciudad de Antequera, que declaró que había hecho diferentes obras y reparos en la iglesia parroquial, según la dirección y disposición que debía ejecutar el maestro Cristóbal García ${ }^{29}$, difunto, y maestro arquitec-

26 Archivo Histórico Provincial de Málaga (AHPM). Sección Protocolos Notariales Pueblos, Cañete la Real, escribanía de Pedro Alcántara Ramírez, legajo P. 6161, s/f.

27 Ibídem. s/f

28 A.G.A.S. Sección III: Justicia. Serie: Fábrica, Pueblos, legajo 11.766.

29 Interesante figura del Barroco, autor de la iglesia de Madre de Dios de Antequera y de otras obras de esta ciudad. 
to de esa ciudad. La declaración es sumamente interesante por el número y alcance de la intervención:

En primer lugar, "entabicar y desentabicar distintos pedasos de toda labor colaterales y en las dos ultimas de la nave de enmedio".

En segundo lugar, "abierto y masisar distintas raxas de las expresadas naves y de la media naranja de dicha Iglesia".

En tercer lugar, "se echaron claves nuevas a casi todos los arcos de dicha Iglesia... y al exterior también se blanqueó la iglesia de dos manos” desde el 25 de abril al 23 de junio de este presente año.

Declaró tener más de 54 años, y no firmó porque no sabía. Fue dado en Antequera el 15 de noviembre de 1757.

En otro excepcional documento del que no se tenía noticia, en relación con los efectos del terremoto de 1755, hay que incluir la declaración -ante el escribano público de Cañete la Real Francisco Albarrán- de Fray Sebastián Padilla, religioso lego profeso de la Orden Tercera Descalzos de Nuestro Padre San Francisco, en su convento de la ciudad de Antequera y maestro de Arquitectura en la provincia de Andalucía ${ }^{30}$. En ella expuso que por disposición de D. José Rivas Acuña y Carvajal, vicario eclesiástico de la iglesia parroquial de San Sebastián, había estado haciendo diferentes obras y reparos en dicha iglesia en la forma en la que debía ejecutarla Cristóbal García, maestro de arquitectura y vecino que fue de la ciudad de Antequera. Además fue el primero que reconoció la iglesia y dio las disposiciones necesarias por orden del vicario. A continuación se detallan cada una de las obras que se realizaron para paliar los efectos sísmicos:

En la torre se hizo un tabique en la salida al tejado principal de la iglesia con su puerta, cerradura y llave, cubierto con canales para impedir el paso a los tejados, como asimismo la acentuada quiebra por estar frontera las entradas por la torre.

Se compuso toda la torre por dentro y algunos escalones que estaban lastimados.

Se tejó de nuevo el tejado inmediato a la torre, por estar todo inservible.

La pared del frontis se cubrió de ladrillo nuevo por la parte superior, y se cogieron con grueso todas las juntas que la unían al tejado. En medio de ella se puso un pilar de piedra, ladrillo y azulejos por haberse caído y roto el que tenía, habiéndose pintado el dicho pilarcito, remate, cornisas, frontis, puerta mayor, como las basas de la iglesia en ocre y almagra. Este aspecto es realmente interesante para conocer el gusto por la aplicación del color a la arquitectura religiosa del setecientos, sobre todo si trasladamos este concepto a algunas intervenciones recientes, cuyo resultado es bastante dudoso y pone en evidencia los escasos criterios que se emplean en la elección del color de estas iglesias parroquiales históricas.

30 A.G.A.S. Sección III: Justicia. Serie: Fábrica, Pueblos, legajo 11.766. 
También se derribó la sacristía vieja a excepción de la pared que caía al corral por estar todavía capaz, y se hizo de nuevo ampliándose a cinco varas de largo y tres más de alta para que quedase la solería al nivel del pavimento de la iglesia. Las paredes se hicieron de ladrillo, piedra, cal y arena. Para las maderas se uso el chopo, se tejó de nuevo toda la sacristía. Las paredes por fuera se hicieron con mezcla fina y se blanqueó dos veces por dentro y por fuera. Se le puso la cornisa al tejado y ventana de ladrillo fino con su pintura y los tejados preparados con sus cadenas para los aires. En el interior se hizo una bóveda de "sinchos y lunetos" de ladrillo doble, como en toda la sacristía, aplicándosele yeso blanco lavado. Se decoraron con molduras y "tanibanillos" los cinchos, mientras que en el testero se hizo de cajones coronado con una almeja de yeso labrado a talla, y a juzgar por el informe la bóveda había quedado bien dispuesta, como requerían las reglas del arte.

Se pusieron en sitio nuevo las taquillas de la sacristía de la iglesia de modo que hicieran juego de cajones. También se terraplenó todo el suelo, que se subió y se puso de losetas mazaríes, además se colocó el aguamanil en otro sitio más cómodo. Se colocaron todas las puertas. En el cuarto taller se arreglaron las rajas de las paredes y se hicieron otras obras importantes, de cara a dar estabilidad a ese espacio. También se blanqueó.

En la lonja o acceso a la iglesia, al haber quedado ésta cortada y con revueltas, tras haberse alargado la sacristía, se hizo una nueva pared para lo que se vació un monte de tierra, cuyo efecto inmediato fue la diafanidad y anchura espacial, al tiempo que se empedró el "Ambito Moderno"; además se quitaron los escombros y se saneó el antiguo empedrado. Se hizo una nueva entrada de gradas y se compusieron las dos paredes que hacían entrada a la puerta principal. En el planning de las obras se incluyeron asear y componer otras oficinas de la iglesia, como el osario que no se podía usar por la acumulación de escombros.

El documento además de detallar las obras que se hicieron, contiene las temporadas en las que se realizaron, así como los trabajadores que lo hicieron posible. Este tipo de información es muy representativa para conocer el mundo laboral de la época, la duración de las obras, los materiales constructivos y ornamentales, el vocabulario arquitectónico, pero también las técnicas empleadas, entre otros aspectos.

El plan de trabajo fue bastante conciso, dividiéndose en cinco temporadas, y en cada una de ellas se hicieron las siguientes intervenciones, recogidas en los cuadros de las páginas siguientes: 
$1^{\text {a }}$ Temporada (Del 4 al 28 de julio de 1758)

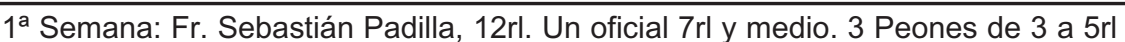
cada uno. 18 días de trabajo, quitando las fiestas hace un total de 621rl. Además, trabajaron en la primera semana: Tomás Villodres 3rl y medio, 4 segadores forasteros 4rl. 1 hijo de Francisco Vivar 3rl.

Total $137 \mathrm{rl}$

$2^{a}$ Semana: Los mismos peones y el hijo de Francisco Vivar ganó medio real más. Otros peones nuevos: Francisco Cueto 4rl. Total $164 \mathrm{rl}$

$3^{\text {a }}$ Semana: Trabajaron los mismos peones.

Total $164 \mathrm{rl}$

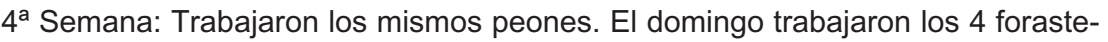
ros y Tomás Villodres, llevando de jornal 19rl y medio al día. Entro nuevo

Cristóbal Ruiz con 3rl y medio para toda la semana.

Total 204rl

Notas: Se incorporó un zagal que ganaba $16 \mathrm{mrs}$ al día por arrimar al tiro los materiales. 16rl que se le pagaron a Fr. Sebastián Padilla por componer sus herramientas.

Por llevar y traer a los maestros de Antequera a Cañete se pagaron 48rl.

$2^{\mathrm{a}}$ Temporada (Del 23 de agosto a finales de septiembre de 1757)

Fr. Sebastián Padilla por 33 días de trabajo 396rl.

$1^{\text {a }}$ Semana: José de Guerra y Melchor Tenorio trabajaron 4 días, cada uno a 3rl.

Total $24 \mathrm{rl}$

$2^{a}, 3^{a}$ y $4^{a}$ Semana: Trabajaron los mismos peones y entraron de nuevo,

Francisco García, Francisco Hartura y Antonio Vaca, a 3rl.

Total 270rl

$5^{\mathrm{a}}$ y $6^{\mathrm{a}}$ Semana: Trabajaron 3 peones.

Total $108 \mathrm{rl}$

$3^{\mathrm{a}}$ Temporada (Primero de octubre al 19 de noviembre de 1757)

Trabajo del maestro, 39 días.

Total $468 \mathrm{rl}$

$1^{\mathrm{a}}, 2^{\mathrm{a}}$ y $3^{\mathrm{a}}$ Semana: Tres peones a $3 \mathrm{rl}$.

Total 262 rl

$4^{\text {a Semana: Tres peones }} \quad$ Total 58rl y medio

$5^{a}$ y $6^{a}$ Semana: Pedro Padilla, oficial de la villa de Teba, 6rl. Los 3 peones y otro

más, Cristóbal Aragón.

Total 190rl

$7^{\text {a }}$ Semana: Trabajó José de Guerra.

Total $21 \mathrm{rl}$ 


\begin{tabular}{|c|c|}
\hline \multicolumn{2}{|l|}{$4^{a}$ Temporada (desde el 9 de mayo 1758) } \\
\hline $\begin{array}{l}9 \text { mayo. Un peón para traer tierra a la sacristía. } \\
1^{\text {a }} \text { Semana: } 1 \text { oficial llamado Pedro Rodríguez, } 6 r l \text { y medio. } 2\end{array}$ & $\begin{array}{r}\text { Total } 2 \mathrm{rl} \\
\text { peones, Francisco }\end{array}$ \\
\hline Rodríguez y Alonso Contero, 3rl cada uno. & Total 50rl \\
\hline $2^{\mathrm{a}}$ Semana: Los mismos trabajadores con igual sueldo. & Total $75 \mathrm{rl}$ \\
\hline $3^{\text {a }}$ Semana: Trabajaron 5 días la misma cuadrilla. & Total 62 rl y medio \\
\hline $4^{a}$ Semana: Trabajaron 3 días los mismos peones y 1 oficial. & Total $37 \mathrm{rl}$ \\
\hline
\end{tabular}

$5^{\mathrm{a}}$ Temporada (Se comenzó el 10 de octubre de 1758)

$1^{\mathrm{a}}, 2^{\mathrm{a}}$ y $3^{\mathrm{a}}$ Semana: Trabajaron los oficiales y peones anteriores, 18 días.

Total $243 \mathrm{rl}$

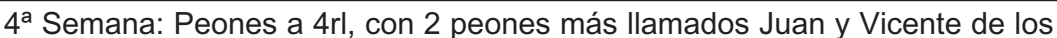
Reyes, más los jornales del maestro oficial. Total $135 \mathrm{r}$ $5^{\text {a }}$ y $6^{\text {a }}$ Semana: Trabajaron sólo el oficial y Francisco Rodríguez. Total 126rl Unos muchachos que trajeron piedra para empedrar la lonja. Por cada espuerta 1 ochavo. Total $9 \mathrm{rl}$ y $32 \mathrm{mrs}$ Por la cal para blanquear el cuarto taller. Total 6rl y $2 \mathrm{mrs}$ A Juan de Anaya, por mondar las cañas del tejado de dicho cuarto. Total 6rl Por hiscal el tejado del cuarto. Total $11 \mathrm{rl}$ y $17 \mathrm{mrs}$ Por mano del que declara se dieron 48rl por los derechos de la declaración que hizo en Antequera el primer maestro de la obra. Total $48 \mathrm{rl}$

Total de la obra ascendió a $4121 \mathrm{rl}$ con $20 \mathrm{mrs}$

El documento fue escriturado en Cañete la Real el día 2 de diciembre de 1758, y lo firmaron el escribano y Fr. Sebastián Padilla31.

Otro documento con fecha de 12 de agosto de 1760 es una declaración de Pedro de Silva, maestro mayor de fábricas del Arzobispado de Sevilla, tras la visita realizada a Cañete la Real sobre las obras realizadas también con motivo del terremoto de 1755 en la parroquia de San Sebastián. Es interesante por varias razones la primera porque en todo el documento no se cita la intervención o colaboración de

31 Lo encontramos en 1758 tasando varios inmuebles pertenecientes a D. Miguel de Dueñas por un valor de 60 reales. AHPM. Sección Protocolos Notariales Pueblos, Cañete la Real, escribanía de Francisco Albarrán, legajo P. $6161, \mathrm{~s} / \mathrm{f}$ 
Q: artículos Eduardo Asenjo Rubio

otros maestros, como Ignacio de Bogas, Cristóbal García, y especialmente la de Fr. Sebastián Padilla, quien finalmente asumió el trabajo y lo llevó a término; únicamente se refiere a las obras encargadas inicialmente al maestro Tomás José Zambrano ${ }^{32}$. En general, teniendo en cuenta el alto nivel de burocratización de la administración durante la Edad Moderna, así como el férreo control que ejercían los visitadores, los administradores y finalmente los maestros arquitectos en el reconocimiento de las obras, es difícil pensar que los trabajos dirigidos por Fr. Sebastián Padilla en 1758 se hubieran realizado sin la autorización y aprobación pertinente. Quizás podría pensarse, dada la proximidad de la intervención en la parroquia y el documento de 1760, que Pedro de Silva manejara como información primaria el presupuesto dado por Tomás José Zambrano, 14450 reales y que difiere enormemente del montante final, 4121 reales, según documento de Fr. Sebastián Padilla, aunque el maestro mayor de fábricas declaró que el coste final ascendió a 14900 reales. Hasta el momento, la única explicación probable es que algunos de los expedientes que contiene el legajo sobre la construcción de la parroquia de Cañete la Real se hayan extraviado. Además, otro aspecto que llama la atención de este documento es la ausencia de información reiterativa, ya que habitualmente solía hacerse una memoria inicial, recopilando todos los datos. En este caso sólo hay un punto de partida, el presupuesto y las obras del maestro Zambrano, y no se recogen las vicisitudes del inmueble.

A la vista de estos datos, de lo que no cabe duda es que la parroquia de San Sebastián tuvo una vida constructiva muy intensa en dos años, si tenemos en cuenta los dictámenes analizados. De hecho, el informe de Pedro de Silva proporciona jugosas noticias sobre las obras que finalmente se llevaron a cabo en 1760, como por ejemplo, las seis bóvedas que inicialmente se habían mandado derribar se repararon exterior e interiormente, así como los arcos y las paredes que estaban agrietadas. Otra de las intervenciones importantes fue la sacristía, cuyas paredes no se echaron a bajo como estaba previsto, sino que se alargó ocho varas y media, sumando un total de 15 varas y media, que difieren de las cinco varas realizadas por Fr. Sebastián Padilla. En lo que sí coinciden ambos informes es que se cubrió con bóveda de cañón con lunetos y se tabicó doble, aunque el arquitecto trinitario especifica que se decoró con molduras.

Otro aspecto menos tratado y conocido de esta iglesia son los enterramientos, algo muy común en las iglesias hasta que el rey Carlos III prohibió su exhumación en su interior por la Real Cédula de 3 de abril de 1787, posteriormente modificada. Carlos IV en su Novísima Recopilación siguió las disposiciones legislativas de su padre e insistió para que éstas se cumplieran. D. José de Ribas Acuña y Carvajal, cura y beneficiado propio de la capilla de Cañete la Real quería comprar un sitio para sepultura, la que estaba a la entrada de la entrada principal. Se argumentaba que había muchas en todo el ámbito de la iglesia, y en ese sitio al considerarse un lugar

32 A.G.A.S. Sección III: Justicia. Serie: Fábrica, Pueblos, legajo 11.766. 
inferior a nadie le apetecía enterrarse allí, por lo que se pidió que se compusiera la loza o señal para distinguir el sitio. Se solicitó a Fray Sebastián Padilla, religioso lego de Nuestro Padre San Francisco de la Provincia de Terceros Descalzos de Andalucía y maestro de arquitectura de dicha provincia, y residente en Cañete desde hacía 6 años, que visitara el sitio y emitiese informe, autorizando la sepultura el 11 de julio de $1762^{33}$

En los protocolos notariales del año 1758 se inserta un memorial de 14 de octubre de 1756, en el que Juan Bautista Pérez, presbítero y mayordomo de fábrica de la iglesia parroquial de Cañete, declaró la pobreza en la que se encontraba el inmueble y que por orden del provisor se mandaba dar 6.000 reales de vellón para la obra de la iglesia. Al no tener más bienes que unas casas cubiertas de teja en la C/ Grande, debido a un alcance al mayordomo anterior Pedro Ramírez, el visitador general D. Juan Martín de Oliva dio licencia mediante decreto para que se vendiera en pública subasta 34 .

Hay que destacar de la abundante documentación que se ha conservado de la parroquia de San Sebastián, las cuentas de la obra para el período de 1765-1768, dadas por Antonio de Figueroa, maestro alarife, durante las 33 semanas que trabajó en Cañete la Real35.

En 1783 Julián Martínez, maestro herrero y cerrajero de la villa de Osuna dijo que en la última visita realizada se dejó un mandato -cuando hubiera dinero- y se hiciera un retablo para el Sagrario, una crujía desde el coro hasta la grada que subía al altar mayor y un monumento, bajo la intervención del vicario ${ }^{36}$.

La visita de 1786 duró del 7 al 9 de julio. En ella como era habitual había una primera valoración del inmueble:

"La Ylgesia Parroquial es de buena construcción, tiene tres hermosas y espaciosas naves, regularmente adornada de altares, y surtida su sacristía, de todo lo necesario para el culto Divino: su [prio], y solado, sin embargo de los frecuentes enterramientos, que son la causa comun del desaseo de las Iglesias está aquí menos malo, y se advierte que ai cuidado, y vigilancia en los reparos, y composiciones necesarias" 37 .

Este documento es muy completo por la información que ofrece sobre Cañete la Real, su hospital, conventos y ermitas.

En esta visita pudo comprobarse que la fábrica de San Sebastián estaba completamente saneada, con 17.773 reales de sobrante, teniendo en cuenta que su

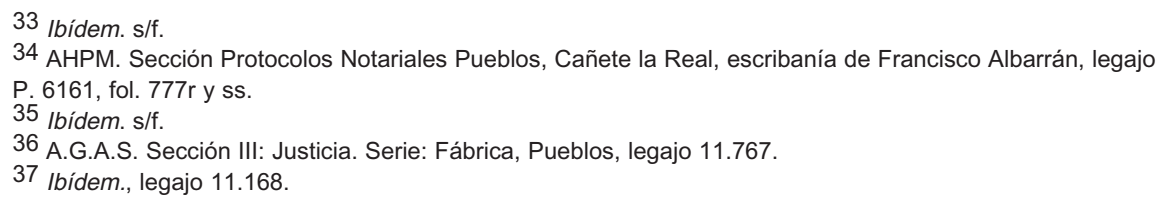


renta anual por un quinquenio era de 15.360 reales de gastos ordinarios. Las obligaciones anuales ascendían a 7.692 reales, y por sobrantes para gastos extraordinarios había 7.668 reales.

Aporta diversas noticias sobra la población de la villa, por ejemplo, que contaba con 600 vecinos y eran devotos. Se hizo constar en el libro de visitas la inexistencia de escándalos públicos, ni desórdenes graves.

En otro punto se informa sobre diferentes inmuebles de la ciudad y sus caudales, que por lo excepcional de los comentarios, creo oportuno integrarlos en este artículo. El hospital de San José que asistía a enfermos pobres contaba con pocos caudales, pero bien invertidos según las cuentas tomadas al capellán. La renta anual oscilaba en torno a los 5.314 reales, destinándose para la curación de enfermos 3.601 reales y los 1.710 restantes para pagar diferentes salarios. Se apostilló en el informe lo reducido de la sala de las enfermas y que carecía de la correspondiente ventilación. Se ordenó que se agrandara, proporcionándole algún terreno, condicionado a que hubiera algún sobrante a favor del hospital. En cuanto a las ermitas se limita a nombrar las seis que existían, cinco en la villa: el Dulce Nombre de Jesús, Nuestra Señora de la Soledad, Nuestra Señora de los Remedios, del Carmen, Señora Santa Ana ${ }^{38}$. En zona despoblada se encontraba la de Nuestra Señora del Carmen de la Vega. Estas ermitas son un buen ejemplo de las que se erigieron en las villas y ciudades que se incorporaron a la corona de Castilla tras concluir el proceso de Conquista en 1492, resignificándose el territorio musulmán en cristiano, adquiriendo nuevos significados acorde con el espíritu de religiosidad popular. Esa vía religiosa fue apoyada y potenciada posteriormente por el Concilio de Trento, que abogó por un contacto emocional y didáctico entre el creyente y la divinidad ${ }^{39}$. En esas ermitas se consagraban las imágenes de mayor devoción para la comunidad. La mayoría de ellas están estrechamente vinculadas a la tradición oral, y en su mayoría se tratan o bien de advocaciones espontáneas o se identificaban con un acontecimiento milagroso.

Sobre los dos conventos menciona que en el de Religiosos Franciscanos recoletos de la Provincia de San Diego había doce sacerdotes, un corista, un lego y cuatro donados; y en el de las Carmelitas recoletas descalzas, bajo la advocación del Santísimo Sacramento, veinte monjas de velo negro y seis de velo blanco, "exemplares en su vida y costumbres, y que siempre an conservado el rigor de su disciplina sin flojedad, ni relajación."

En 28 de junio de 1787 Francisco de Acosta, artífice tallista y arquitecto de Sevilla y su arzobispado, reconoció el Monumento que tenía en venta la Hermandad del Santísimo Sacramento de la iglesia parroquial de Santa María la Blanca en

38 En muchos casos, la elección de la advocación está íntimamente ligada con el uso y producción de la tierra.

39 BOUZA ÁlVAREZ, J. L.: Religiosidad Contrarreformista y cultura simbólica del Barroco. Madrid, CSIC, 1990. 
Sevilla, y que quería adquirir la parroquia de San Sebastián de Cañete la Real. De su declaración podemos extraer una imagen muy clara del bien mueble: presentaba unos cimientos que servían de base al primer cuerpo de arquitectura, realizado en orden dórico con cuatro columnas que se disponían en ángulo recto, y que recogía en el centro el espacio reservado para la custodia dorada con columnas y era de planta circular. Dicho espacio era de orden corintio compuesto por 12 columnas de las que destacaban cuatro y sobre las que descansaba cada uno de los evangelistas. Se cerraba con cuatro cartelones coronados por la Fe. El segundo cuerpo del Monumento era de orden jónico, siguiendo las reglas de la arquitectura. En él destacaba la imagen del Salvador en lienzo pintado. El último cuerpo, de menor tamaño, era de orden corintio y en su interior exhibía un Señor de la columna. El Monumento se remataba con una cúpula y tres cruces. Su altura era de diez varas, y de anchura cinco y media. El único inconveniente del reconocimiento era que dicho mueble necesitaba componerse y arriostrarse la mayoría de sus piezas. Se tasó en 600 ducados. A la cifra anterior había que unir el traslado a Cañete, cuyo costo ascendía a 1.800 reales, sin incluir la asistencia y manutención de los oficiales, que correría a cargo de la fábrica de Cañete.

El expediente sobre los reparos que debían realizarse en el órgano de la iglesia es realmente excelente, primero por su dilatación en el tiempo, desde 1767 a 1800 , segundo por la abundancia de datos sobre los diferentes dictámenes del bien mueble. El primero en reconocer, evaluar y proponer su composición fue Francisco Pérez de Valladolid, artista organero mayor del Arzobispado. Tras visitar la parroquial de Cañete informó que el órgano se encontraba "derrotado" debido al rayo que había caído en el templo, provocando que hiciera: "pedazos los pilares..."

La visita del 24 de octubre de 1802 dio como resultado una iglesia parroquial decente, bien servida de ornamentos y con bastante plata. La iglesia tenía un sobrante de 32.782 reales y 20 maravedíes, que debían invertirse en un tabernáculo con puerta forrada de plata para el altar mayor, y solar la iglesia 40 .

En general, la visita de 1805 dejo una valoración poco positiva de la iglesia, señalándose que en la iglesia y la sacristía faltaba el orden y el aseo correspondiente, encontrándose con frecuencia las lámparas apagadas. La limpieza y el estado de los ornamentos era una de las preocupaciones del provisor. Debía componerse la puerta alta del Sagrario alto, llenándola y dorando el hueco de la cerradura antigua. También debía componerse y afirmarse el copón del sagrario alto, ya que se encontraba flojo. Se reiteraron otros mandamientos que se habían incumplido en 1798 , como fundir y hacer de nuevo las crismeras de la pila bautismal. Debía revisarse la pila bautismal porque perdía agua y en todo caso hacerse una de nuevo. También había que hacer una campana al estar rota la vieja. Respecto a la fábrica, se encargaba al mayordomo que debía recorrer con frecuencia los tejados para evitar goteras y otros daños ${ }^{41}$. Con una Guerra de Independencia en pleno auge era lógico que

40 A.G.A.S, Sección II Gobierno, Serie Libros de visitas, legajo 1523, año 05153. 
los mandamientos para la iglesia de Cañete fueran continuistas y con escasas inversiones, las justas para mantener el inmueble.

Una de las últimas descripciones que tenemos de la parroquia de San Sebastián antes de los sucesos de 1936, pertenece al párroco D. Cayetano Espinosa. Ofrece interesantes noticias especialmente sobre el estado de conservación de la parroquia a comienzos del siglo XX, así como las obras y los donantes que las hicieron posible. Estos datos son cruciales sobre todo por la profunda reforma que se produjo del inmueble tras la contienda bélica. "Tanto las columnas como los pilares son de piedra, hoy pintada de amarillo con los capiteles blanqueados...El pavimento es de mármol de Coin, blanco y negro y fue colocado el año 1905 con donativo que hizo D. Antonio Talavera Jiménez." Los desastres alcanzaron a muchos bienes muebles de los que desconocemos su cronología y autoría, ya que todos ellos desaparecieron, y sólo se ha conservado esta referencia textual, bien significativa:

"Posee un coro bajo con sillería de nogal de veintitrés asientos. El del centro tiene en el respaldo un alto relieve representando la imagen de la Inmaculada Concepción y un doselete de madera. Cierra el coro una cancela de listones torneados de madera, y dos puertas laterales de dos hojas. Encima de la cancela hay dos esculturas y un Crucifijo pequeños, y dos campanarios de tres campanillas cada uno. La cancela y puerta con cerrojos."

En el mismo sentido se encuentra el órgano, y aunque ya nos hemos referido a él, ahora podemos mencionar que su ubicación "sobre el lado derecho de Coro... fue reconstruido en 30 de abril de 1900 por el maestro organero Don Modesto Carrettol. Importó la restauración dos mil setecientas pesetas, de las cuales donó dos mil el Pro., de esta villa Don Francisco Solís Montilla, y setecientos el Pro., también de esta villa Don Francisco Arjona y Castano."

Una escueta pero sentida nota del cura encargado de Cañete la Real, D. Anselmo González, dirigida al Cardenal Arzobispo de Sevilla el 20 de octubre de 1936, no sólo relataba las pérdidas producidas durante la contienda bélica, sino también proporciona noticias sobre el número de capillas públicas existentes en la villa, de las que no teníamos conocimiento: “...con el mayor dolor participa a V. E. R que con fecha 25 de julio último y por los marxistas incalificables fueron desmanteladas, saqueadas y desvalijadas esta Iglesia parroquial y siete capillas públicas que existen en esta villa. Hasta el presente solo algunas prendas sueltas se han podido encontrar para conocimiento de V. E. R...42".

\footnotetext{
41 Ibídem. s/f

42 A.G.A.S. Sección II: Gobierno. Serie: Asuntos Despachados, legajo 05096.
} 